\title{
The Champions We Produce Tomorrow Will be the Result of the Efforts We Put in Today
}

\author{
Akshay Soni* \\ Sport of Sciences, India \\ *Corresponding Author: Akshay Soni, Sport of Sciences, India.
}

DOI: 10.31080/ASOR.2020.03.0141

Game after game, competition after competition we as the audience or coaches demand better results, trophies and medals. Whether it be an international competition or a local one, coming out at the top remains our goal.

Let's reverse this process, from winning to the daily intense practice we all are aware of repetitive effort in and out that is executed by the athlete, coach and even the family. Let's not discard the impact of family and environmental support in raising a topclass athlete.

When it comes to health and sports we are often inspired by these elite-level athletes to pursue physical activity and fitness.

Growing up, becoming adults, many of us forget this aspect and the motivation usually boils down as a result of lack of discipline and habit forming starting from an early age.

As a result, we have people hiring fitness and sports coaches, using nutrition tracking applications and consuming information in an attempt to help them get back to fitness or enhance their health.

We all can relate to the above process as adults and have been a part of the same, Also as a nation, we are aware of the rise in lifestyle diseases such as obesity and diabetes to name a few.

Coming back to sports, we know deliberate practise and repetitive effort is one of the key factors to becoming a successful athlete and from our experience as an adult, we know the value of early habit-forming and discipline.
Received: January 24, 2020

Published: January 27, 2020

(C) All rights are reserved by Akshay Soni.
Children are falling prey to these same diseases and inactivity. I wouldn't blame technology for the same but the lack of an appropriate grassroots system for lifetime health and top-level sports.

We have to educate parents, coaches and children to become physically active whether it be to become an elite level athlete or to stay disease-free and improve quality of life

How do we that?

With the rise of private companies in this sector and efforts by individual government, I would say we are pretty well on track when it comes to awareness.

But performance?

Not really, the above products are not creating the output they promise. Not in my experience.

Most of my research done to understand what companies are bringing in has led to disappointment. Being a part of the same process, I understand it from a business perspective but as a coach, I know that the solution is not optimal.

Mimicking or licensing foreign models and trying to execute it in our culture at the local level is what most are trying to do and failing to fulfil their promises of producing elite athletes or fitter children.

There can be several solutions and everyone can have a different perspective but science can't be refuted.

We need to come together, at the local level, understand our culture and devise models that promote fundamentals that carry 
over long term performance as mentioned above repetitive effort, habit-forming, discipline to name a few of many.

When we start to imbibe these fundamentals through programs, coaching and parenting is when the outcome of any activity or sport taken up will produce results in multifold.

This is what I call the inside-out approach, no program can mask what's not developed within and I firmly believe that Cultivate the fundamentals, programs can act as a cherry.

\section{Assets from publication with us}

- Prompt Acknowledgement after receiving the article

- Thorough Double blinded peer review

- Rapid Publication

- Issue of Publication Certificate

- High visibility of your Published work

Website: https://www.actascientific.com/

Submit Article: https://www.actascientific.com/submission.php

Email us: editor@actascientific.com

Contact us: +919182824667 